\title{
The Reliability and Validity of the Three Modified Versions of the Children's Fear Survey Schedule-Dental Subscale of 9-12 Year Old Children in a Clinical Setting in Bosnia and Herzegovina
}

\author{
Elmedin Bajrić1, Sedin Kobašlija ${ }^{1}$, Hrvoje Jurić ${ }^{2}$, Amina Huseinbegović ${ }^{1}$, \\ Amila Zukanović ${ }^{1}$
}

${ }^{1}$ Department of Preventive and Pediatric Dentistry, Faculty of Dentistry of Sarajevo University, Bosnia and Herzegovina ${ }^{2}$ Department of Paediatric and Preventive Dentistry, School of Dental Medicine, University of Zagreb, Croatia

\author{
Correspondence: \\ elmedinbajric@gmail.com \\ Tel.: + 38733407872 \\ Fax.: + 38733443395
}

Received: 19 October 2017

Accepted: 21 March 2018

Key words: Dental fear and anxiety - Children $\cdot$ CFSS-DS scale $\cdot$ Modified versions - Reliability and validity.
Objectives. This study sought to obtain a comprehensive, reliable and valid instrument for evaluation of the presence of dental fear and anxiety (DFA) in children, through evaluation of the reliability and validity of three modified versions of the Children's Fear Survey Schedule-Dental Subscale (CFSS-DS). Materials and Methods. The study sample comprised children aged 9, 10, 11 and 12 years. The first sample group (200 patients) filled in a modified version of the CFSSDS scale, the second sample group (100 patients) filled in a short form of the Dental Fear Survey Schedule, and the third sample group (100 patients) filled in a short version of the CFSS-DS scale, prior to dental treatment, respectively. In order to determine test-retest reliability, the 184 patients from the first sample group filled in the modified version of the CFSS-DS scale again, prior to their next scheduled dental appointment. Results. The modified version of the CFSS-DS scale had the best internal consistency reliability ( $\alpha=0.907)$, as well as validity results, compared to the other two instruments used. Test-retest reliability was moderate (Intraclass correlation coefficient: 0.58 ). Conclusions. Of the three psychometric instruments used for evaluation of DFA presence in children, the modified version of the CFSS-DS scale showed the most clinically adequate reliability and validity values. This study thus provides a new psychometric instrument that should be considered for clinical use in evaluation of DFA presence in 9-12 year-olds, in a clinical setting sample type of children.

\section{Introduction}

To date, the instrument most used for measuring dental fear and anxiety (DFA) in children has been the Children's Fear Survey Schedule-Dental Subscale (CFSS-DS), also known as the Dental Fear Survey Schedule for Children (DFSS-C). The CFSS-DS scale was designed by Cuthbert and Malamed in 1982, and was based on a wider instrument for measuring fear in children, the Children's Fear Survey Schedule (CFSS) (1), designed in 1967 by Scherer and Nakamura, and also known as the Fear Survey Schedule for Children (FSS-FC) (2).

The CFSS-DS scale has 15 questions (items) covering dental (invasive and non- 
invasive treatment procedures), medical and general situations. The answers range on a Likert scale from 1 (not afraid) to 5 (very afraid), with a total scale score between 15 and 75 . There are parent and child versions of the CFSS-DS scale, depending on who answers the questions, the child or a parent (1). These two versions of the scale have been used in numerous studies, in patients aged from 3.5 to 19 years, for evaluation of DFA presence, in many countries (3-9). This scale was the most preferred in many studies compared with other measuring instruments for evaluation of DFA presence, due to its better psychometric characteristics and wider range of DFA related aspects. The CFSS-DS scale has good reliability but variable validity (4-9). In a previous study it was determined that the CFSS-DS scale had good internal consistency reliability (Cronbach $\alpha=0.861$ ). Factor analysis revealed four factors that together explained the $63.79 \%$ variance of results (6).

However, some CFSS-DS scale validity results in several studies conducted showed that some of the scale items did not contribute much to explaining the variance of results (4-9). As a result, some shortened modifications of the CFSS-DS scale have appeared. Carson and Freeman suggested a shorter form of the CFSS-DS scale with 8 scale items in 1997, and in 2005 Rantavuori et al. also published studies with a shortened CFSS-DS scale of 10 scale items, and in 2004 and 2012 there were studies with a shortened scale of 11 scale items. The solid variable normative value of these scales has been reported, with various limitations and suggestions for further research $(4,10-12)$. This showed that the authors tended to correct the disadvantages of the CFSS-DS scale and to create an instrument that covers all aspects of DFA presence, but mostly by shortening it $(4,10-12)$. Also, the previous research showed that there is room for managing the content of the scale to improve its capability of differing between children with and those without DFA (6).

Therefore, the aim of this study was to obtain a single comprehensive, reliable and valid instrument for evaluation of DFA, in order to measure more precisely its presence in children, to determine its reliability and validity values, and to compare it with the other two shortened versions of the CFSSDS scale.

\section{Patients and methods}

\section{Participants and study design}

The study sample was clinical and comprised of a specific population of children, who were randomly selected patients who attended the Clinic of Preventive and Pediatric Dentistry of the Faculty of Dentistry of Sarajevo University, in the period between January and October 2013. The reason for their visit to the Clinic was a permanent tooth carious lesion of medium depth (dentinal depth of the lesion corresponded with ICDAS code 5), which had to be resolved according to the dental treatment plan. This reason was the main criterion for inclusion in the study, in order to avoid other potential biases in the clinical setting. The patients were aged 9, 10,11 and 12 years. The reason for choosing this age group was the general cognitive and psychosocial development of the children $(13,14)$. In order to avoid selection bias, child behavior in the dental office was evaluated and medical history was determined where it was necessary, so that children with general psychological problems could be excluded from the study sample. The patients' parents signed an informed consent form for the participation of their children in this study, and the assent of the child patients was also obtained.

Prior to the scheduled dental treatment, clear instructions were given to the child participants regarding participation in the 
study, and the patients provided answers to the three modifications of the CSSS-DS scale in the dental office, as follows: a modified version of the Children's Fear Survey Schedule-Dental Subscale, the Carson and Freeman Short Form of the CFSS-DS scale (4) and the 10-item Short Version of CFSSDS scale designed by Rantavuori et al. (10), respectively. This was undertaken in order to compare the reliability and validity values of these three modifications of the CFSSDS scale. Accordingly, the sample consisted of three groups, where the patients were assigned randomly to one of them. The number of patients in the groups was determined according to the statistical minimum that was sufficient for conducting analyses of the reliability and validity values of these scales (15). So, the child participants responded to the scale questions by themselves, without any help from the researchers or their parents. When the children finished, the researchers immediately collected the questionnaires from the child participants, just before the scheduled dental treatment started.

The first sample group of 200 patients filled in the modified version of the Children's Fear Survey Schedule-Dental Subscale (CFSS-DS-mod scale). The CFSS-DS-mod scale was revised in its design in comparison with the original CFSS-DS scale as follows: it was reduced by removing items that were not related to the dentist or the treatment, and at the same time extended with new dental (treatment) situations which were not in it originally. The reason for this modification was the previous research with the original CFSS-DS scale, where it was determined that some of the scale items did not improve its normative value, and also the fact that not all clinical dental situations were included in this instrument (6). The previous studies by others had also led to this conclusion (4-5, 7-9). As a result, a new scale was created, the CFSS-DS-mod scale, originally in the Bosnian language. For the purpose of this publication, the scale items were translated into English by a licensed translator (Table 1), and back-translated into Bosnian in order to avoid any bias in the meaning of the items.

The CFSS-DS mod scale had 17 items (questions) which were adapted to the patients according to their meaning. The idea was to include all situations related to the dentist, the dental office and dental treatment. So, the CFSS-DS-mod scale design comprised four categories, as follows: general terms (dentist), being in the waiting room and in the dental office itself, various forms and stages of dental treatment, as well as the notion of dental pain. Eight items from the original CFSS-DS scale remained, but two of these were combined in the new scale. The meaning of two of the original items was changed, so that eight new items were added to the scale. These items were also first translated by a licensed translator for English language, and back-translated into Bosnian prior to their use. The answers to this new scale questions ranged on a 5-point Likert scale from 1 (not afraid) to 5 (very afraid). The total CFSS-DS-mod scale score ranged from 17 to 85 .

The second sample group of 100 patients filled in the Short Form of the Dental Fear Survey Schedule (DFSS-SF) (4). It consisted of eight items. For the purpose of this study the DFSS-SF scale items were first translated into English and back-translated into Bosnian by a licensed translator, prior to their use, in order to avoid any potential bias in the meaning of the items. Similarly to the previous scale, eight items of the DFSS-SF scale were excluded from the original CFSSDS scale, and one item about tooth extraction was added (4). The answers to the questions were coded by the 5-point Likert scale, from 1 (not afraid) to 5 (very afraid). The total score ranged from 8 to 40 (4).

The third sample group of 100 patients filled in the Short Version of the CFSS-DS 
Table 1. The Modified Version of the Children's Fear Survey Schedule-Dental Subscale

\begin{tabular}{|c|c|c|c|c|c|c|}
\hline \multicolumn{2}{|c|}{ Questions } & \multirow{2}{*}{$\begin{array}{l}\begin{array}{l}\text { Not } \\
\text { afraid }\end{array} \\
1\end{array}$} & \multirow{2}{*}{$\begin{array}{l}\begin{array}{l}\text { Slightly } \\
\text { afraid }\end{array} \\
2\end{array}$} & \multirow{2}{*}{ 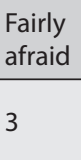 } & \multirow{2}{*}{$\begin{array}{l}\text { Quite } \\
\text { afraid }\end{array}$} & \multirow{2}{*}{$\begin{array}{l}\begin{array}{l}\text { Very } \\
\text { afraid }\end{array} \\
5\end{array}$} \\
\hline 1. & $\begin{array}{l}\text { Are you afraid of being in the waiting room before entering the dental } \\
\text { office? }\end{array}$ & & & & & \\
\hline 2. & $\begin{array}{l}\text { Are you afraid of being } \\
\text { in the dental office? }\end{array}$ & 1 & 2 & 3 & 4 & 5 \\
\hline 3. & Are you afraid of the dentist? & 1 & 2 & 3 & 4 & 5 \\
\hline 4. & $\begin{array}{l}\text { Are you afraid of people } \\
\text { in white uniforms? }\end{array}$ & 1 & 2 & 3 & 4 & 5 \\
\hline 5. & $\begin{array}{l}\text { Are you afraid of sitting in } \\
\text { the dental chair? }\end{array}$ & 1 & 2 & 3 & 4 & 5 \\
\hline 6. & $\begin{array}{l}\text { Are you afraid when the dentist examines your mouth with dental } \\
\text { instruments? }\end{array}$ & 1 & 2 & 3 & 4 & 5 \\
\hline 7. & $\begin{array}{l}\text { Are you afraid when you keep } \\
\text { your mouth open? }\end{array}$ & 1 & 2 & 3 & 4 & 5 \\
\hline 8. & Are you afraid of the suction device in your mouth? & 1 & 2 & 3 & 4 & 5 \\
\hline 9. & Are you afraid when the dentist cleans your teeth from dental plaque? & 1 & 2 & 3 & 4 & 5 \\
\hline 10. & Are you afraid when your teeth are being drilled? & 1 & 2 & 3 & 4 & 5 \\
\hline & $\begin{array}{l}\text { Are you afraid of the sound of dental } \\
\text { drilling devices? }\end{array}$ & 1 & 2 & 3 & 4 & 5 \\
\hline 12. & Are you afraid of the sight of dental drilling devices? & 1 & 2 & 3 & 4 & 5 \\
\hline 13. & Are you afraid of the dental syringe? & 1 & 2 & 3 & 4 & 5 \\
\hline 14. & Are you afraid of the dental syringe needle? & 1 & 2 & 3 & 4 & 5 \\
\hline 15. & Are you afraid of tooth extraction? & 1 & 2 & 3 & 4 & 5 \\
\hline 16. & $\begin{array}{l}\text { Are you afraid of dental treatment } \\
\text { that causes pain? }\end{array}$ & 1 & 2 & 3 & 4 & 5 \\
\hline 17. & $\begin{array}{l}\text { Are you afraid when you are unable to breathe during dental } \\
\text { treatment? }\end{array}$ & 1 & 2 & 3 & 4 & 5 \\
\hline
\end{tabular}

scale (CFSS-SV) (10). It consisted of 10 items. For the same reasons as with the other two scales used in this study, translation into English language and back translation into Bosnian was undertaken by a licensed translator. In the design of the CFSS-SV scale seven items were excluded from the original CFSS-DS scale, and two items were added about pain during dental treatment and the presence of a suction device in the mouth (10). The answers to the questions were coded by the 5-point Likert scale, from 1 (not afraid) to 5 (very afraid). The total score ranged from 10 to 50 (10).

In order to determine the test-retest reliability of the CFSS-DS-mod scale, a retest evaluation of DFA presence by this scale had to be conducted. According to the previously established dental treatment plan, 184 patients from the first group of 200 patients, who came back to resolve a carious lesion of a permanent tooth of medium depth, answered the same CFSS-DS-mod scale questions again, under the same dental office conditions, prior to their scheduled treatment. This was undertaken after one month from their first study test sample visit, consecutively for each patient. The rest of the 16 patients missed their scheduled appointment and were excluded from the study retest sample.

\section{Ethics statement}

This research was approved by the Ethical Committee of the Faculty of Dentistry of Sarajevo University, and also was conducted according to the Declaration of Helsinki (16). 


\section{Statistical analysis}

The results obtained from this study were statistically processed as follows:

- Descriptive values were presented by descriptive statistics (frequency of the study participants by their age in percentages, mean values and standard deviations of age, and of the scores of the different scales used in the study sample groups);

- The Cronbach a coefficient was calculated as the internal consistency reliability of the three scales, altogether with the corrected item-total correlations presented for each of scale items;

- The test-retest reliability of the CFSS-DSmod scale was determined by calculating an intra-class correlation coefficient (ICC);

- The construct validity of the three scales was determined by explorative factor analysis (EFA) applying varimax rotation. The criteria for proper factor analysis were determined by the KaiserMeyer-Olkin test of sampling adequacy (KMO) and the Bartlett test of sphericity (Bartlett). Percentage and cumulative percentage of explained variance, as well as determined Eigen values, were presented.

All statistical analyses were obtained for a $\mathrm{P}<0.05$ significance level in the IBM Statistical Package for Social Science software (version 23.0) for the Windows operative system.

\section{Results}

The descriptives of the study sample were as follows: The first sample group contained 58 (29\%), 44 (22\%), 53 (26.5\%) and 45 (22.5\%) patients aged $9,10,11$ and 12 years, respectively. The mean group age was $10.43 \pm 1.13$ years. The mean CFSS-DS-mod scale score was 27.52 \pm 9.21 . The second sample group

Table 2. Internal consistency reliability of CFSS-DS-mod, DFSS-SF and CFSS-SV scales

\begin{tabular}{|c|c|c|c|c|c|}
\hline \multicolumn{2}{|c|}{ CFSS-DS-mod scale } & \multicolumn{2}{|l|}{ DFSS-SF scale } & \multicolumn{2}{|c|}{ CFSS-SV scale } \\
\hline$(n=200)$ & & $(n=100)$ & & $(n=100)$ & \\
\hline $\begin{array}{l}\text { Cronbach } \\
a=0.907\end{array}$ & $\begin{array}{l}\text { Corrected item- } \\
\text { total correlations }\end{array}$ & $\begin{array}{l}\text { Cronbach } \\
a=0.650\end{array}$ & $\begin{array}{l}\text { Corrected item- } \\
\text { total correlations }\end{array}$ & $\begin{array}{l}\text { Cronbach } \\
a=0.800\end{array}$ & $\begin{array}{l}\text { Corrected item- } \\
\text { total correlations }\end{array}$ \\
\hline Item 1 & 0.536 & Item 1 & 0.592 & Item 1 & 0.553 \\
\hline Item 2 & 0.672 & Item 2 & 0.311 & Item 2 & 0.420 \\
\hline Item 3 & 0.421 & Item 3 & 0.497 & Item 3 & 0.335 \\
\hline Item 4 & 0.243 & Item 4 & 0.342 & Item 4 & 0.618 \\
\hline Item 5 & 0.655 & Item 5 & 0.113 & Item 5 & 0.573 \\
\hline Item 6 & 0.657 & Item 6 & 0.267 & Item 6 & 0.427 \\
\hline Item 7 & 0.465 & Item 7 & 0.475 & Item 7 & 0.177 \\
\hline Item 8 & 0.445 & Item 8 & 0.474 & Item 8 & 0.658 \\
\hline Item 9 & 0.595 & - & - & Item 9 & 0.410 \\
\hline Item 10 & 0.670 & - & - & Item 10 & 0.671 \\
\hline Item 11 & 0.687 & - & - & - & - \\
\hline Item 12 & 0.652 & - & - & - & - \\
\hline Item 13 & 0.510 & - & - & - & - \\
\hline Item 14 & 0.583 & - & - & - & - \\
\hline Item 15 & 0.582 & - & - & - & - \\
\hline Item 16 & 0.763 & - & - & - & - \\
\hline Item 17 & 0.618 & - & - & - & - \\
\hline
\end{tabular}


Acta Medica Academica 2018;47:1-10

Table 3. Validity results of the three modifications of the CFSS-DS scale

\begin{tabular}{|c|c|c|c|c|c|c|c|c|}
\hline \multicolumn{3}{|c|}{ CFSS-DS-mod scale } & \multicolumn{3}{|c|}{ DFSS-SF scale } & \multicolumn{3}{|c|}{ CFSS-SV scale } \\
\hline \multicolumn{3}{|l|}{$(n=200)$} & \multicolumn{3}{|c|}{$(n=100)$} & \multicolumn{3}{|l|}{$(n=100)$} \\
\hline \multicolumn{3}{|l|}{$\mathrm{KMO}=0.880$} & \multicolumn{3}{|c|}{$\mathrm{KMO}=0.562$} & \multicolumn{3}{|c|}{$\mathrm{KMO}=0.763$} \\
\hline \multicolumn{3}{|c|}{ Bartlett $P<0.0005$} & \multicolumn{3}{|c|}{ Bartlett $\mathrm{P}<0.0005$} & \multicolumn{3}{|c|}{ Bartlett $\mathrm{P}<0.0005$} \\
\hline \multirow{2}{*}{ Items } & \multicolumn{2}{|c|}{ Factors:* } & \multirow{2}{*}{ Items } & \multicolumn{2}{|c|}{ Factors:* } & \multirow{2}{*}{ Items } & \multicolumn{2}{|c|}{ Factors:* } \\
\hline & 1 & 2 & & 1 & 2 & & 1 & 2 \\
\hline Item 10 & 0.795 & 0.212 & Item 7 & 0.835 & 0.099 & Item 10 & 0.776 & -0.127 \\
\hline Item 9 & 0.716 & 0.195 & Item 8 & 0.791 & 0.109 & Item 8 & 0.772 & 0.172 \\
\hline Item 2 & 0.710 & 0.309 & Item 1 & 0.626 & 0.237 & Item 4 & 0.744 & -0.094 \\
\hline Item 6 & 0.658 & 0.339 & Item 4 & 0.618 & -0.017 & Item 1 & 0.693 & 0.291 \\
\hline Item 5 & 0.621 & 0.382 & Item 2 & 0.449 & -0.046 & Item 5 & 0.684 & -0.029 \\
\hline Item 16 & 0.617 & 0.520 & Item 5 & -0.193 & 0.750 & Item 6 & 0.572 & 0.091 \\
\hline Item 11 & 0.595 & 0.459 & Item 3 & 0.455 & 0.715 & Item 2 & 0.518 & -0.098 \\
\hline Item 12 & 0.549 & 0.454 & Item 6 & 0.101 & 0.673 & Item 9 & 0.510 & -0.276 \\
\hline Item 3 & 0.511 & 0.140 & - & - & - & Item 7 & 0.254 & 0.694 \\
\hline Item 1 & 0.503 & 0.344 & - & - & - & Item 3 & 0.422 & -0.615 \\
\hline Item 4 & 0.455 & -0.074 & - & - & - & - & - & - \\
\hline Item 14 & 0.099 & 0.828 & - & - & - & - & - & - \\
\hline Item 13 & 0.014 & 0.817 & - & - & - & - & - & - \\
\hline Item 15 & 0.252 & 0.667 & - & - & - & - & - & - \\
\hline Item 17 & 0.422 & 0.539 & - & - & - & - & - & - \\
\hline Item 7 & 0.277 & 0.483 & - & - & - & - & - & - \\
\hline Item 8 & 0.242 & 0.482 & - & - & - & - & - & - \\
\hline$\%$ Variance & 27.122 & 22.490 & - & 31.910 & 20.084 & - & 37.973 & 10.934 \\
\hline$\%$ Cumulative & 27.122 & 49.613 & - & 31.910 & 51.995 & - & 37.973 & 48.907 \\
\hline Eigen value & 7.027 & 1.407 & - & 2.794 & 1.366 & - & 3.799 & 1.091 \\
\hline
\end{tabular}

$\mathrm{KMO}=$ Kaiser-Meyer-Olkin test of sampling adequacy; ${ }^{*}$ The loading factors of scales Items are presented by their descending value.

contained 26 (26\%), 15 (15\%), 24 (24\%) and $35(35 \%)$ patients aged $9,10,11$ and 12 years, respectively. The mean group age was $10.68 \pm 1.21$ years. The mean DFSS-SF scale score was $10.71 \pm 2.83$. The third sample group contained 25 (25\%), 27 (27\%), 25 (25\%) and $23(23 \%)$ patients aged $9,10,11$ and 12 years, respectively. The mean group age was $10.46 \pm 1.1$ years. The mean CFSS-SV scale score was $15.82 \pm 5.17$.

Table 2 shows the results of internal consistency reliability, with corrected item-total correlations for the three modifications of the CFSS-DS scale. It was shown that the Cronbach coefficient had the highest value in the CFSS-DS-mod scale $(\alpha=0.907)$. The corrected item-total correlations also had the highest values in this scale. The lowest internal consistency reliability was found using the DFSS-SF scale $(\alpha=0.650)$, and in the CFSS-DS-mod scale the lowest corrected item total correlation was for the 4 th item (fear of people in white uniforms; $r=0.243$ ). The first retest sample group showed dropout of $8 \%$ (16 of the 200 patients). Test-retest reliability showed a value of ICC $=0.58$, 
$\mathrm{P}<0.0005$. No statistically significant differences were determined between the study participants and those who dropped out.

Table 3 shows the results of explorative factor analysis (EFA) with Varimax rotation for the three modifications of the CFSS-DS scale, with KMO and Bartlett test values. All three scales obtained two-factor solutions, with the Eigen values of extracted factors which were greater than 1 . The total variance explained was around 50\% (from 48.907\% to $51.995 \%)$. Although the DFSS-SF and CFSS-SV scales showed two-factor solutions with a solid percentage of the variance of its results explained, in the case of the DFSS-SF scale, KMO was 0.576 , and also in the CFSSSV scale, in the second factor, the 3rd item had negative factor loading ( $\mathrm{r}=-0.615)$. On the other hand, in the CFSS-DS-mod scale, two factors were also extracted, which explained $49.613 \%$ of the variance of results obtained with this scale. The first factor was related mostly to the dentist and dental staff, the dental office and its contents, as well as non-invasive dental procedures. The second factor was mostly related to invasive dental procedures.

\section{Discussion}

The internal consistency reliability estimated with the CFSS-DS-mod scale demonstrate its excellent reliability value according to the $a$ ranking evaluation $(\geq 0.9)$. However, the relatively low corrected item-total correlation for question no. 4. "Fear of people in white uniforms", would suggest that this item was perhaps in disparity with the list of factors for DFA appearance in the CFSS-DSmod scale. All the other items had a value above 0.3 . On the basis of this and the results of factor analysis, we suggest that the CFSSDS-mod scale measures mostly the same underlying concept, the presence of DFA in children. Test-retest reliability in contrast showed a moderate ICC value. The test reli- ability and reproducibility in general usually depends upon many factors, such as sample size and quality, instrument design and its homogeneity, the retest period, etc. Although this reliability should be considered as questionable, since the usual acceptable threshold value is 0.7 , sometimes authors regard a test-retest reliability threshold value of 0.6 as possible $(15,17)$.

Although the DFSS-SF and CFSS-SV scales served more as controls, they did show lower internal consistency reliability values. They also had a few corrected itemtotal correlations values below 0.3 , and this decreased with the increase of the number of items per scale.

We have already emphasized that the situations related to the dentist and the staff, the dental office and its contents, as well as non-invasive dental procedures mostly had two-factor solutions of the CFSS-DS-mod scale as the first factor. So, it seemed that the most provoking factors for the presence of DFA tended to create one side of its twodimensional concept, putting every other component on the other side. However, the high first factor loadings also had items such as fear of tooth drilling, as well as fear of pain caused by dental treatment. Preparation of a carious lesion is certainly an invasive dental procedure, but it affects body integrity less than two other well-known dental interventions - tooth extraction and dental local anesthesia administration. So, it should not be surprising that these three were separated from one another. The fear of pain caused by dental procedures also had high second factor loadings, so this item by nature should probably belong to the second factor.

The results of EFA for the DFSS-SF and CFSS-SV scales were questionable. In order for the conditions for proper conduct of the EFA to be met, KMO had to be $\geq 0.6$, and the Bartlett test of sphericity (Bartlett) had to be $\mathrm{P}<0.05$ (15). In the case of the DFSS-SF scale this condition of the KMO minimal value 
Table 4. Review of the studies where the CFSS-DS scale and its modifications were used and its reliability and validity values were determined

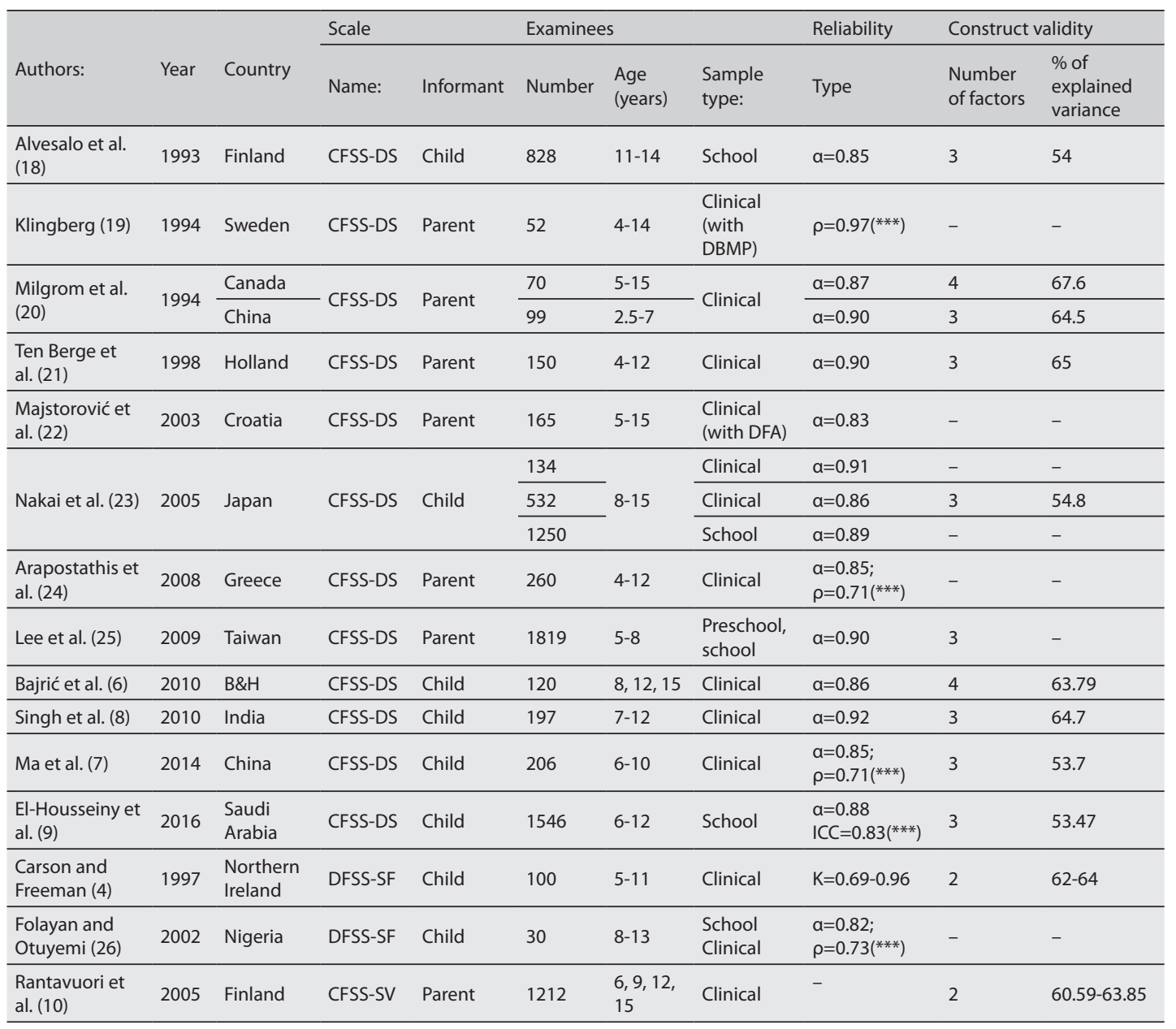

$\mathrm{DBMP}=$ Dental Behavior Management Problems; ${ }^{* * *} \mathrm{P}<0.0005$.

was not achieved, so there were no minimal statistical reasons for this factor analysis to be considered appropriate. On the other hand, the negative second factor loading of one of two items made the CFSS-SV scale two-factor solution unsustainable for at least two reasons. The first reason is that the loading was negative, which meant that this item explained the second factor in the opposite way. If we were to exclude it from the second factor, then only one 7 th item would remain. The extracted factor with only one item in it would not be statistically possible (15). These are the reasons why we should not consider the construct validities of the DFSS-SF and CFSS-SV scales as proper ones.

In Table 4 several studies are shown of evaluation of DFA presence, where the reliability and validity values of the CFSS-DS scale used and its modifications are presented. Besides different methodologies (sample size, age and type, type of informant), compared to the original CFSS-DS scale, the modified scale version from this study had mostly higher a values of internal consistency reliability $(6-9,18-25)$. This 
was also the case compared to the DFSS-SF and CFSS-SV scales (which we confirmed), although fewer studies have been conducted $(4,10,26)$. In contrast, the original scale and its two modifications showed better construct validity concerning the $\%$ of total variance explained, but the number of extracted factors remained variable $(4,6-10$, $18,20-21,23)$. Nevertheless, the over $50 \%$ of variance in our scale remained unexplained. Although the original design of the CFSSDS-mod scale had four categories, the scale items were latently grouped into two factors. The number of 200 cases for conducting the EFA was statistically minimal, and sample size is one of the most important conditions for its proper execution (15).

\section{Limitations and improvements}

The results obtained from this study showed some limitations (possible selection bias of patients in the clinical setting, and no comparison with the original design of the CFSS-DS scale, for example), as well as ways of improving and further analysis of the CFSS-DS-mod scale, in terms of a larger and wider sample size with a non-clinical setting sample type, type of informant, conducting confirmatory factor analysis, cut-off score evaluation, socio-economic state, etc., so that the normative values of this scale could be evaluated in the general population.

\section{Conclusion}

This study provided a new psychometric instrument for evaluation of DFA presence in 9-12 year olds, in a clinically setting sample type of children, in the form of the CFSS-DSmod scale. This instrument showed good reliability and validity values, and therefore should be considered for clinical use in determining DFA presence in children.
What is already known on this topic

Dental fear and anxiety is a widespread clinical phenomenon which may seriously interfere with dental treatment. The instrument used by far the most for measuring dental fear and anxiety in children is the Children's Fear Survey ScheduleDental Subscale.

\section{What this study adds}

The results from our study provide a new instrument based on the Children's Fear Survey Schedule-Dental Subscale, for evaluation and validation of the presence of dental fear and anxiety in children.

Acknowledgements: This study was conducted on the basis of the significant human efforts of the dental health care personnel of the Clinic for Preventive and Pediatric Dentistry of the Faculty of Dentistry, Sarajevo University.

Authors' contributions: Conception and design: EB, SK, HJ, AH and AZ; Acquisition, analysis and interpretation of data: EB, SK, HJ, AH and AZ; Drafting the article: $\mathrm{EB}, \mathrm{SK}, \mathrm{HJ}, \mathrm{AH}$ and $\mathrm{AZ}$; Revising it critically for important intellectual content: EB, SK, HJ, AH and $\mathrm{AZ}$; Approved final version of the manuscript: EB, SK, $\mathrm{HJ}, \mathrm{AH}$ and $\mathrm{AZ}$.

Conflict of interest: The authors declare that they have no conflict of interest.

\section{References}

1. Cuthbert MI, Melamed BG. A screening device: children at risk for dental fears and management problems. ASDC J Dent Child. 1982;49(6):432-6.

2. Scherer MW, Nakamura CY. A fear survey schedule for children (FSS-FC): a factor analytic comparison with manifest anxiety (CMAS). Behav Res Ther. 1968;6(2):173-82.

3. Klingberg G, Broberg AG. Dental fear/anxiety and dental behaviour management problems in children and adolescents: a review of prevalence and concomitant psychological factors. Int J Paediatr Dent. 2007;17(6):391-406.

4. Carson P, Freeman R. Assessing child dental anxiety: the validity of clinical observations. Int J Paediatr Dent. 1997;7(3):171-6.

5. Porritt J, Buchanan H, Hall M, Gilchrist F, Marshman Z. Assessing children's dental anxiety: a systematic review of current measures. Community Dent Oral Epidemiol. 2013;41(2):130-42.

6. Bajrić E, Kobašlija S, Jurić H. Reliability and validity of Dental Subscale of the Children's Fear Survey Schedule (CFSS-DS) in children in Bos- 
nia and Herzegovina. Bosn J Basic Med Sci. 2011;11(4):214-8.

7. Ma L, Wang M, Jing Q, Zhao J, Wan K, Xu Q. Reliability and validity of the Chinese version of the Children's Fear Survey Schedule-Dental Subscale. Int J Paediatr Dent. 2015;25(2):110-6.

8. Singh P, Pandey RK, Nagar A, Dutt K. Reliability and factor analysis of children's fear survey schedule-dental subscale in Indian subjects. J Indian Soc Pedod Prev Dent. 2010;28(3):151-5.

9. El-Housseiny AA, Alsadat FA, Alamoudi NM, El Derwi DA, Farsi NM, Attar MH, et al. Reliability and Validity of the Children's Fear Survey Schedule-Dental Subscale for Arabic-Speaking Children: a Cross-Sectional Study. BMC Oral Health. 2016;16:49.

10. Rantavuori K, Lahti S, Seppä L, Hausen H. Dental fear of Finnish children in the light of different measures of dental fear. Acta Odontol Scand. 2005;63(4):239-44.

11. Rantavuori K, Lahti S, Hausen H, Seppä L, Kärkkäinen S. Dental fear and oral health and family characteristics of Finnish children. Acta Odontol Scand. 2004;62(4):207-13.

12. Rantavuori K, Tolvanen M, Lahti S. Confirming the factor structure of modified CFSS-DS in Finnish children at different ages. Acta Odontol Scand. 2012;70(5):421-5.

13. Welbury RR. Pediatric dentistry. 3rd ed. Oxford: Oxford University Press; 2005.

14. Wood SE, Wood CE, Boyd D. Mastering the World of Psychology. 2nd ed. Boston: Pearson Allyn \& Bacon; 2006.

15. Tabachnick BG, Fidell LS. Using Multivariate Statistics. 6th ed. Boston: Pearson Education; 2013.

16. World Medical Association. World Medical Association Declaration of Helsinki: ethical principles for medical research involving human subjects. JAMA. 2013;310(20):2191-4.

17. Terwee CB, Bot SD, de Boer MR, van der Windt DA, Knol DL, Dekker J, et al. Quality criteria were proposed for measurement properties of health status questionnaires. J Clin Epidemiol. 2007;60(1):34-42.

18. Alvesalo I, Murtomaa H, Milgrom P, Honkanen A, Karjalainen M, Tay KM. The Dental Fear Survey Schedule: a study with Finnish children. Int J Paediatr Dent. 1993;3(4):193-8.

19. Klingberg G. Reliability and validity of the Swedish version of the Dental Subscale of the Children's Fear Survey Schedule, CFSS-DS. Acta Odontol Scand. 1994;52(4):255-6.

20. Milgrom P, Jie Z, Yang Z, Tay KM. Cross-cultural validity of a parent's version of the Dental Fear Survey Schedule for children in Chinese. Behav Res Ther. 1994;32(1):131-5.

21. ten Berge M, Hoogstraten J, Veerkamp JS, Prins PJ. The Dental Subscale of the Children's Fear Survey Schedule: a factor analytic study in The Netherlands. Community Dent Oral Epidemiol. 1998;26(5):340-3.

22. Majstorovic M, Veerkamp JS, Skrinjaric I. Reliability and validity of measures used in assessing dental anxiety in 5- to 15-year-old Croatian children. Eur J Paediatr Dent. 2003;4(4):197-202.

23. Nakai Y, Hirakawa T, Milgrom P, Coolidge T, Heima M. The Children's Fear Survey ScheduleDental Subscale in Japan. Community Dent Oral Epidemiol. 2005;33(3):196-204.

24. Arapostathis KN, Coolidge T, Emmanouil D, Kotsanos N. Reliability and validity of the Greek version of the Children's Fear Survey Schedule-Dental Subscale. Int J Paediatr Dent. 2008;18(5):374-9.

25. Lee CY, Chang YY, Huang ST. Higher-order exploratory factor analysis of the Dental Subscale of Children's Fear Survey Schedule in a Taiwanese population. Community Dent Health. 2009;26(3):183-7.

26. Folayan MO, Otuyemi OD. Reliability and validity of a short form of the dental subscale of the child fear survey schedule used in a Nigerian children population. Niger J Med. 2002;11(4):161-3. 